\title{
4.5 Defective phosphorylation of the interleukin 18 receptor beta-chain causes impaired NK cell function in systemic onset Juvenile Idiopathic Arthritis
}

\author{
W de Jager*1, SJ Vastert ${ }^{1}$, JM Beekman ${ }^{2}$, NM Wulffraat ${ }^{1}$, W Kuis ${ }^{1}$, PJ Coffer ${ }^{2}$
} and BJ Prakken ${ }^{1}$

Address: ${ }^{1}$ Pediatric Immunology, UMC Utrecht, Utrecht, Netherlands and ${ }^{2}$ Molecular Immunology, UMC Utrecht, Utrecht, Netherlands

* Corresponding author

from I5th Paediatric Rheumatology European Society (PreS) Congress

London, UK. 14-17 September 2008

Published: 15 September 2008

Pediatric Rheumatology 2008, 6(SuppI I):S9 doi:10.1I86/1546-0096-6-SI-S9

This abstract is available from: http://www.ped-rheum.com/content/6/SI/S9

(c) 2008 de Jager et al; licensee BioMed Central Ltd.

Systemic onset Juvenile Idiopathic Arthritis (SoJIA) is an autoimmune disease characterised by arthritis and systemic features. Cytokines like IL1, IL6 and IL18 are thought to be responsible for clinical symptoms. IL18 can drive NK cell function. Recently we showed high IL18 levels in plasma correlate with disease activity in SoJIA [1]. Since SoJIA patients have diminished NK cell function we investigated the functionality of these cells in relation to IL18.

All cell culture experiments were performed with IL18 in the presence or absence of IL12.

SoJIA patients $(\mathrm{n}=15)$ show significant lower NK cells present in peripheral blood and a differential NK cell receptor phenotype is present compared with pJIA patients $(n=15)$ and healthy controls $(n=10)$. No difference in IL18 receptor expression was observed. Furthermore IL18 in plasma of SoJIA patients is able to drive NK cell function of healthy controls and is able to bind the IL18 receptor.

However, SoJIA patients fail to upregulate cell mediated killing molecules, such as perforin and IFN $\gamma$ after IL18 stimulation, nor does IL18 induce phosphorylation of several MAP kinases (ERK1/2 and JNK). Both pJIA patients and healthy controls show phosphorylation of MAP kinases which results in upregulation of cell medi- ated killing molecules such as IFNg and perforin after stimulation with IL18.

We were able to pinpoint the mechanism of the impaired NK cell - IL18 axis to an IL18 receptor defect. This important observation has major implications for understanding the immunepathogenesis of SoJIA.

\section{References}

I. de Jager W, et al:: Blood and synovial fluid cytokine signatures in patients with juvenile idiopathic arthritis: a cross-sectional study. Ann Rheum Dis 2007, 66:589-598. 